\title{
The spread of blood parasitic diseases in dogs in Barnaul city
}

\author{
N.V. Tikhaya ${ }^{*}$, N.M. Ponamarev, M.Yu. Novikova, Yu.N. Fisenko, and S.L. Plotnikova \\ FSBEI of HE Altai State Agrarian University, Barnaul, Russia
}

\begin{abstract}
Most blood parasitoses are transmitted by means of carriers ticks or insects, which bodies undergo certain development stages or transmission is carried out mechanically. Dirofilariasis is a zoonotic disease of animals and humans carried by mosquitoes. The reasons for dirofilariasis spread are the unrestricted movement of animals from one region to another. To diagnose dirofilariasis, a microscopy method of a fresh blood drop was used. Diagnosis for babesiosis in animals was made based on clinical traits and results of microscopic examination of peripheral blood smears stained according to Romanovsky-Gimza. The study of the ixodic ticks' prevalence as distribution sources of dog babesiosis was carried out in Barnaul in different parts of the city. The spring rise of babesiosis begins in late April and ends at the end of May, the summer period June-July is characterized by a low incidence rate. The autumn rise is from August to October, i.e., it coincides with ticks' activity during this period. The incidence of ticks in Barnaul is not uniform. The largest range of ticks' distribution is found in the highland part of the city.
\end{abstract}

\section{Introduction}

The Altai Krai is located in the south-eastern part of Western Siberia and borders with the following subjects of the Russian Federation: in the north - with the Novosibirsk region, on the north-east - with the Kemerovo region, in the south-east - with the Republic of Altai. In the south and south-west, the border of the Altai Krai coincides with the state border of Russia with the Republic of Kazakhstan [1].

The most warm and dry is the flat western part of the region, which creates favorable conditions for the existence of species diversity of ticks and insects - carriers of infections and development of natural and focal diseases [2, 3].

Most blood parasitoses are transmitted by means of carriers - ticks or insects, which bodies undergo certain development stages or transmission is carried out mechanically [4, $5]$.

Such diseases include babesiosis and dirofilariasis in dogs.

Babesiosis is a blood parasitic disease of domestic and wild mammals characterized by the phenomena of fever, anemia and yellowness of the mucous membranes, hemoglobinuria. Untimely treatment or its absence leads to the death of the animal $[5,6,7]$.

${ }^{*}$ Corresponding author: tikhaya.n@mail.ru 
Dirofilariasis is a zoonotic disease of animals and humans carried by mosquitoes. The causes of dirofilariasis spread are the unrestricted movement of animals from one region to another, restriction of chemical protection usage against midges; In the city of Barnaul, $D$. immitis is recorded quite often [8].

The aim of the work was to study epizootology of blood parasitic diseases in the city of Barnaul.

The objectives of our research included:

- determine the spread of babesiosis and dirofilariasis in dogs in Barnaul.

- determine the species composition of ticks of the Ixsodidae family and insects of the Culicidae family and the timing of their activity and distribution.

\section{Materials and methods of research}

Experimental studies were carried out at the Department of Microbiology, Epizootology, Parasitology and Veterinary and Sanitary Expertise of the Altai State University, as well as in the KSBI VB in Barnaul in the Central Veterinary Hospital. In the course of the work, the obtained data analysis of the animals' laboratory studies registration journal in the Central Veterinary Hospital in the period from 2012 to 2019 was carried out; in addition, 2,932 blood samples from dogs of different genders, ages and breeds were selected for the study.

Diagnosis in animals was made based on clinical traits and results of microscopic examination of peripheral blood smears stained according to Romanovsky-Gimza. To diagnose dirofilariasis, a microscopy method of a fresh blood drop was additionally used [8].

The study of the ixodic ticks' prevalence as distribution sources of dog babesiosis was carried out in Barnaul in different parts of the city. The collection of ixodic ticks was carried out with the help of white honeycomb cloth on the territory of forests, urban areas, parks, squares, in recreation areas, in landscaped yards, on animals' exercising areas. Also, mites were removed from animals admitted to the veterinary hospital of Barnaul. A total of 2,458 specimens of live ticks were collected. Species affiliation of ixodic ticks were determined with the help of the determinant by Kerbabaea E.B., Vasilevich F.I. (2000) [9].

Species composition of bloodsucking insects was studied in different areas of the foreststeppe zone of Barnaul. Insects' collection was carried out according to the technique of V.A. Polyakov (1990) in the morning, lunchtime and in the evening for 7 days. Mosquitoes were collected with entomological net by carrying out 8-10 swings. Insects were taken out of the net and placed in a jar with a lid. They were further placed on a foam mat. $[10,11]$ Insects' species affiliation was determined using the determinant by Plavilshchikov N.I. (1998) [12].

\section{Results of the study}

The studies have resulted in the following data presented in Table 1.

Table 1. Number of studied blood samples from dogs from 2012 to 2019

\begin{tabular}{|l|l|c|c|c|c|}
\hline $\begin{array}{l}\text { N } \\
\text { o. }\end{array}$ & Disease name & $\begin{array}{c}\text { Total samples } \\
\text { studied }\end{array}$ & $\begin{array}{c}\text { Negative } \\
\text { reaction } \\
\text { samples }\end{array}$ & $\begin{array}{c}\text { Positive } \\
\text { reaction } \\
\text { samples }\end{array}$ & \% of lesion \\
\hline 1. & Dirofilariasis & 1419 & 1230 & 189 & 13,3 \\
\hline 2. & Babesiosis & 1513 & 898 & 615 & 40,6 \\
\hline & Total: & 2932 & - & - & - \\
\hline
\end{tabular}


Table 1 shows that the percentage of dog lesion with dirofilariasis in the city of Barnaul accounts for $13.3 \%$ of the number of samples studied, babesiosis $-40.6 \%$, which confirms the wide spread of these diseases.

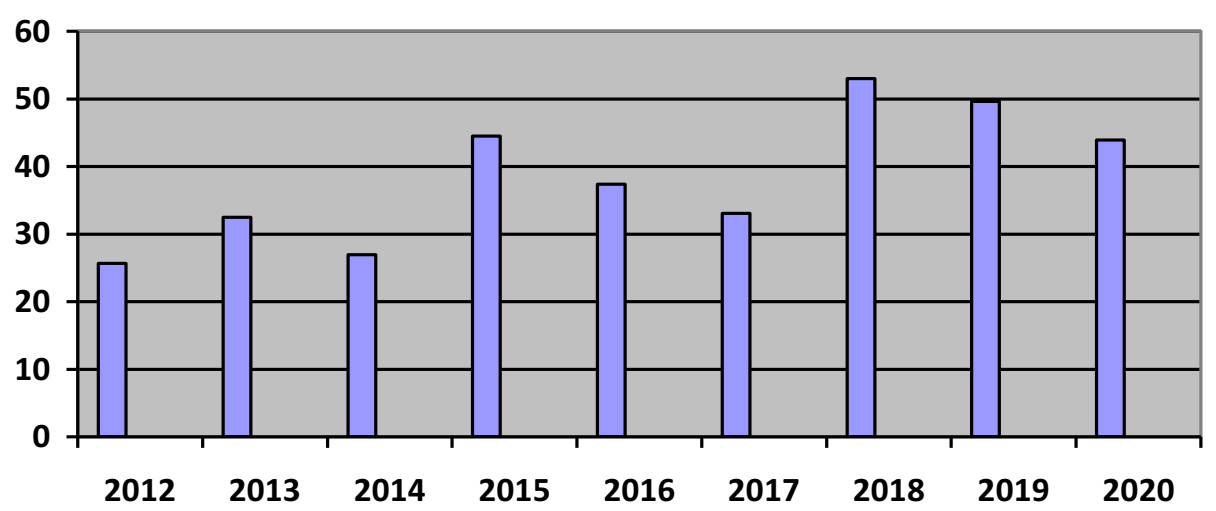

Fig. 1. Annual dynamics of detected babesiosis cases in the city of Barnaul.

Figure 1 shows the annual dynamics of detected disease cases in Barnaul, dogs' lesion with babesiosis by year amounts to $25.64 \% ; 32.5 \% ; 26.96 \% ; 44.48 \% ; 37.39 \% ; 33.07 \%$; $53.0 \% ; 49.6 \% ; 43.9$ respectively. The largest percentage of animal lesions was observed in $2018-53.0 \%$ and in $2019-49.6 \%$.

Table 2. Lesion of different dog breeds with ixodic ticks in the spring period for 2017-2020.

\begin{tabular}{|l|c|c|c|c|c|c|c|c|}
\hline \multirow{2}{*}{$\begin{array}{l}\text { Dogs' breed } \\
\text { composition }\end{array}$} & \multirow{2}{*}{$\begin{array}{c}\text { Q-ty if } \\
\text { animals }\end{array}$} & Q-ty of ticks & \multicolumn{2}{|c|}{$\begin{array}{c}\text { Dermacentor } \\
\text { marginatus }\end{array}$} & \multicolumn{2}{|c|}{$\begin{array}{l}\text { Dermacentor } \\
\text { reticulatus }\end{array}$} & \multicolumn{2}{l|}{$\begin{array}{l}\text { Ixsodes } \\
\text { persulcatus }\end{array}$} \\
\cline { 4 - 10 } & & & Q-ty & $\%$ & Q-ty & $\%$ & Q-ty & $\%$ \\
\hline Mongrel & 30 & 69 & 24 & 34.8 & 31 & 44.9 & 14 & 20.3 \\
\hline Stafford & 27 & 36 & 11 & 30.6 & 16 & 44.4 & 9 & 25.0 \\
\hline Labrador & 12 & 21 & 7 & 33.3 & 9 & 42.9 & 5 & 23.8 \\
\hline $\begin{array}{l}\text { American } \\
\text { Spaniel }\end{array}$ & 18 & 27 & 6 & 22.2 & 12 & 44.5 & 9 & 33.3 \\
\hline Corgi & 9 & 15 & 4 & 26.7 & 8 & 53.3 & 3 & 20.0 \\
\hline $\begin{array}{l}\text { East } \\
\text { European } \\
\text { Shepherd }\end{array}$ & 36 & 51 & 14 & 27.5 & 26 & 51.0 & 11 & 21.5 \\
\hline Total & 132 & 219 & 66 & 30.1 & 102 & 46.6 & 51 & 23.3 \\
\hline
\end{tabular}

Analysis of table 2 shows that among the ticks collected from dogs, the species Dermacentor reticulates predominates - 46.6\%, subdominant species are: Dermacentor marginatus $-30.1 \%$ and Ixsodes persulcatus $-23.3 \%$.

Table 3. Seasonal dynamics of dog lesion with babesiosis

\begin{tabular}{|l|c|c|c|c|}
\hline \multicolumn{1}{|c|}{ Month } & Total samples & $\begin{array}{c}\text { Negative } \\
\text { samples }\end{array}$ & $\begin{array}{c}\text { Positive } \\
\text { samples }\end{array}$ & $\begin{array}{c}\text { Lesion } \\
\text { percentage }\end{array}$ \\
\hline \multicolumn{7}{|c|}{} & 2 & 3 & 4 & 5 \\
\hline \multicolumn{5}{|c|}{$\mathbf{2 0 1 8}$} \\
\hline January & - & - & - & - \\
\hline February & - & - & - & - \\
\hline March & 2 & 2 & 0 & 0 \\
\hline April & 11 & 9 & 2 & 18.2 \\
\hline May & 73 & 23 & 50 & 68,5 \\
\hline
\end{tabular}




\begin{tabular}{|c|c|c|c|c|}
\hline June & 23 & 5 & 18 & 78.5 \\
\hline July & 31 & 21 & 10 & 32.3 \\
\hline August & 30 & 11 & 19 & 63.3 \\
\hline September & 41 & 22 & 19 & 46,3 \\
\hline October & 31 & 17 & 14 & 45.2 \\
\hline November & 3 & 3 & 0 & - \\
\hline December & 0 & 0 & 0 & - \\
\hline Total & 249 & 113 & 132 & 53.0 \\
\hline \multicolumn{5}{|c|}{2019} \\
\hline 1 & 2 & 3 & 4 & 5 \\
\hline January & - & - & - & - \\
\hline February & - & - & - & - \\
\hline March & 3 & 3 & 0 & 0 \\
\hline April & 45 & 19 & 26 & 57.8 \\
\hline May & 38 & 15 & 23 & 60.5 \\
\hline June & 19 & 18 & 1 & 5.3 \\
\hline July & 10 & 9 & 1 & 10.0 \\
\hline August & 31 & 14 & 17 & 54.8 \\
\hline September & 69 & 26 & 43 & 62.3 \\
\hline October & 31 & 18 & 13 & 41.9 \\
\hline November & 6 & 5 & 1 & 16.7 \\
\hline December & 0 & - & - & - \\
\hline Total & 252 & 127 & 125 & 49.6 \\
\hline \multicolumn{5}{|c|}{2020} \\
\hline 1 & 2 & 3 & 4 & 5 \\
\hline January & 1 & 1 & 0 & - \\
\hline February & 1 & 1 & 0 & - \\
\hline March & 2 & 2 & 0 & - \\
\hline April & 41 & 22 & 19 & 46,3 \\
\hline May & 59 & 36 & 23 & 39.0 \\
\hline June & 26 & 23 & 3 & 11.5 \\
\hline July & 13 & 11 & 2 & 15.4 \\
\hline August & 57 & 27 & 30 & 52.6 \\
\hline September & 81 & 32 & 49 & 60.5 \\
\hline October & 34 & 16 & 18 & 52.9 \\
\hline November & 15 & 14 & 1 & 6.7 \\
\hline December & - & - & - & \\
\hline Total & 330 & 185 & 145 & 43,9 \\
\hline
\end{tabular}

The spring rise of babesiosis begins in late April and ends at the end of May, the summer period June-July is characterized by a low incidence rate. Autumn rise is from August to October, i.e., it coincides with the activity of ticks during this period (table 3 ).

When determining genera and species of ticks, we found that this disease is associated with the intensive spread of ixodic ticks in the territory of Barnaul.

The dominant species are ticks from the Ixsodes genus: species Ixsodes

persulcatus; Dermacentor genus: Dermacentor marginatus, Dermacentor reticulatus, Dermacentor corcinna. Ticks of these genera are characterized by a seasonal doublepeaked curve with spring and autumn activity peaks.

The incidence of ticks in Barnaul is not uniform. The largest ticks' distribution range is noted in the highland part of the city, where there is a stripe of coniferous forest and small rivers. 


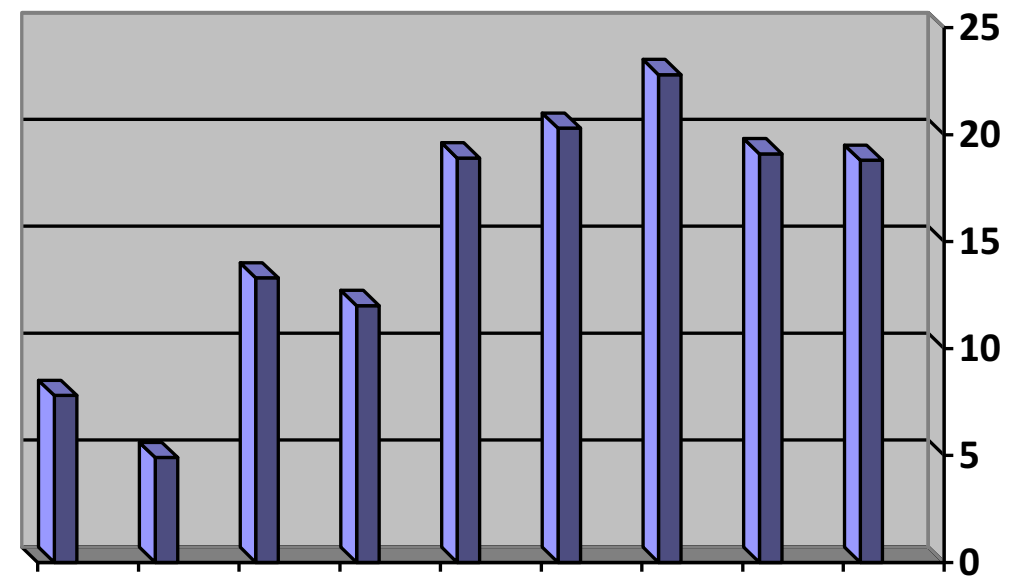

201220132014201520162017201820192020

Fig. 2. Annual dynamics of detected dirofilariasis cases in the city of Barnaul.

Annual dynamics of the detected dirofilariasis cases in Barnaul is shown in Figure 2. The data obtained show that between 2012 and 2020, the percentage of dog lesion with dirofilariasis amounted to $7.8 ; 4.93 ; 3.37 ; 13.29 ; 12.06 ; 18.95 ; 20.3 ; 22.8 ; 19.1 ; 18.8 \%$, respectively. The highest percentage of animal lesions with dirofilariasis was $22.8 \%$ in 2018, which indicates the prevalence of this disease. It should be noted that from 2017 to 2019 , the number of cases of animal lesion with dirofilariasis is not decreasing but are at a fairly high level.

Table 4. Seasonal dynamics of dog lesion with dirofilariasis.

\begin{tabular}{|c|c|c|c|c|}
\hline Month & $\begin{array}{c}\text { Total } \\
\text { samples }\end{array}$ & $\begin{array}{c}\text { Negative } \\
\text { samples }\end{array}$ & $\begin{array}{l}\text { Positive } \\
\text { samples }\end{array}$ & $\begin{array}{c}\text { Lesion } \\
\text { percentage }\end{array}$ \\
\hline 1 & 2 & 3 & 4 & 5 \\
\hline \multicolumn{5}{|c|}{2018} \\
\hline January & 16 & 10 & 6 & 37.5 \\
\hline February & 19 & 16 & 3 & 15.8 \\
\hline March & 7 & 6 & 1 & 14.3 \\
\hline April & 6 & 6 & 0 & - \\
\hline May & 25 & 17 & 8 & 32.0 \\
\hline June & 17 & 12 & 5 & 29.4 \\
\hline July & 13 & 10 & 3 & 23.1 \\
\hline August & 18 & 13 & 5 & 27.8 \\
\hline September & 13 & 9 & 4 & 30.8 \\
\hline October & 15 & 13 & 2 & 13,3 \\
\hline November & 11 & 11 & 0 & - \\
\hline December & 7 & 6 & 1 & 14.3 \\
\hline Total & 167 & 129 & 38 & 22.8 \\
\hline \multicolumn{5}{|c|}{2019} \\
\hline 1 & 2 & 3 & 4 & 5 \\
\hline January & 9 & 9 & 0 & -- \\
\hline February & 16 & 10 & 6 & 37.5 \\
\hline March & 22 & 19 & 3 & 13.6 \\
\hline April & 19 & 17 & 2 & 10.5 \\
\hline May & 22 & 15 & 7 & 31.8 \\
\hline
\end{tabular}




\begin{tabular}{|l|c|c|c|c|}
\hline June & 16 & 12 & 4 & 25,0 \\
\hline July & 18 & 16 & 2 & 11.1 \\
\hline August & 13 & 11 & 2 & 15.4 \\
\hline September & 19 & 16 & 3 & 15.8 \\
\hline October & 11 & 7 & 4 & 36.4 \\
\hline November & 10 & 9 & 1 & 10.0 \\
\hline December & 13 & 11 & 2 & 15.4 \\
\hline Total & $\mathbf{1 8 8}$ & $\mathbf{1 5 2}$ & $\mathbf{3 6}$ & $\mathbf{1 9 . 1}$ \\
\hline \multicolumn{5}{|l|}{} \\
\hline \multicolumn{1}{|c|}{1} & 2020 & 3 & 4 & 5 \\
\hline January & 16 & 14 & 2 & 12.5 \\
\hline February & 19 & 15 & 4 & 21.1 \\
\hline March & 13 & 9 & 4 & 30.8 \\
\hline April & 18 & 13 & 5 & 27.8 \\
\hline May & 13 & 11 & 2 & 15.4 \\
\hline June & 6 & 6 & 0 & - \\
\hline July & 15 & 15 & 0 & - \\
\hline August & 18 & 15 & 3 & 16.7 \\
\hline September & 14 & 13 & 1 & 7.1 \\
\hline October & 11 & 7 & 4 & 36.4 \\
\hline November & 7 & 6 & 1 & 14.3 \\
\hline December & 4 & 1 & 3 & 75.0 \\
\hline Total & $\mathbf{1 5 4}$ & $\mathbf{1 2 5}$ & $\mathbf{2 9}$ & $\mathbf{1 8 . 8}$ \\
\hline
\end{tabular}

Conducted retrospective analysis for 2018-2020 (table 4) of seasonal monthly dynamics did not reveal any pronounced changes due to the long-term larvae development in animals' bodies (6-7 months). Although in the spring and autumn period it is slightly higher.

There are 4 mosquito genera registered within the city of Barnaul: Aedes, Culiceta, Culex, Anopheles. Aedes genus accounts for $97.4 \%$ of the total genera. The dominant species of this genus are: Aedes cinereus, Aedes flavescens, Aedes ciprius, Aedes excrucians. Frequently found are Aedes communis, Aedes punctor, Aedes vexans, Aedes caspius dorsalis.

In the territory of Barnaul, we noticed mosquitoes' activity in the morning from 5.00 to 8.00 hours and in the evening from 19.00 to 23.00 hours, especially in warm cloudy weather and before the rain.

On average, 60 days of mass insects' flight are noted in the territory of Altai Krai. The first flight of mosquitoes begins around the 20th of May and ends at the end of August depending on the natural and climatic conditions causing their breeding period.

\section{Conclusions}

Thus, the average indicator of dog lesion with dirofilariasis amounts to $13.3 \%$, babesiosis $40.6 \%$, which remains an urgent problem.

Spring babesiosis rise begins in late April, autumn - from August, i.e., it matches with the ticks' activity during this period. The incidence of ticks in Barnaul is not uniform. The largest ticks' distribution range is noted in the highland part of the city, where there is a stripe of coniferous forest and small rivers.

In the city of Barnaul, ixodofauna is represented by four species of two ticks' genera: Ixsodes persulcatus, Dermacentor marginatus, Dermacentor reticulatus, Dermacentor corcinna.

The duration of mosquito flight averages 117 days. The first mosquitoes usually appear in the first decade of May, the last - in late August or in the first decade of September. Mass flight of mosquitoes last for an average of 48 days. It largely depends on weather 
conditions in the spring period, which determines their breeding terms. Mosquitoes most actively attack in the morning and evening hours.

\section{References}

1. N.V. Rudakov, Medical and geographical atlas of Altai Krai. Tick-borne zoonoses with natural focus, 80 (2018)

2. N.M. Ponamarev, Diagnosis, treatment, and prevention of animal pyroplasmosis: guidance manual, 31 (2011)

3. N.M. Ponamarev, N.V. Tikhaya, M.Yu. Novikova, Bulletin of Altai State Agrarian University, 5 (163), 136-141 (2018)

4. N.M. Ponamarev, M.Yu. Novikova, N.V. Tikhaya, Russian parasitological journal 14 (2), 46-52 (2020)

5. N.M. Ponamarev, V.G. Onishchenko, N.V. Tikhaya, Bulletin of Altai State Agrarian University 8 (154), 160-164 (2017)

6. S.V. Egorov, Collection "Theory and Practice of Parasitic Diseases Control", 13, 162163 (2012)

7. E.N. Kryuchkova, B.G. Abalikhin, S.V. Egorov, E.A. Sokolov, Collection "Theory and Practice of Parasitic Diseases Control”, 19, 235-236 (2018)

8. N.M. Ponamarev, N.V. Tikhaya, Filariasis of animals: guidance manual, 62 (2010)

9. E.B. Kerbabaev, F.I. Vasilevich, T.S. Kataeva, M.V. Rozovenko, Arachnoentomoses of farm animals, 136 (2000)

10. V.A. Polyakov, U.Ya. Uzakov, G.A. Veselkina, Veterinary Entomology and Arachnology, 360 (1990)

11. N.M. Ponamarev, N.V. Tikhaya, O.E. Nosova, Bulletin of Altai State Agrarian University, 7 (129), 89-92 (2015)

12. N.N. Plavilshchikov, Insect ranger, 388 (1998) 